\title{
SOBRE EL CARAMBOLO: «LA TROMPETA DE ARGANTONIO»
}

\author{
POR
}

ROCÍO IZQUIERDO y JOSÉ LUIS ESCACENA

Departamento de Prehistoria y Arqueología. Universidad de Sevilla

\section{RESUMEN}

Algunos materiales arqueológicos rescatados en El Carambolo han sugerido la existencia en este asentamiento de un posible santuario. Entre estos testimonios se ha olvidado casi sistemáticamente un thymiaterion orientalizante en bronce, porque desde su descubrimiento Carriazo dudó sobre su función. Pretendemos demostrar aquí que esta pieza perteneció en su día a un quemaperfumes ritual, lo que constituye sin duda un apoyo más a la hipótesis que ve en $\mathrm{El} \mathrm{Ca-}$ rambolo un lugar de culto.

\section{SUMMARY}

Artefacts found at El Carambolo have led scholars to suppose that this was a sanctuary site. Among the finds is a bronze thymiaterion of orientalising style. The original excavator's doubts about its purpose has meant that the evidence of this particular piece has been almost wholly ignored by later scholars. Its identification as an incense-burner lends further support for the site's religious character.

\section{INTRODUCCIÓN}

Hasta la fecha, el Cerro del Carambolo, en el término municipal de Camas, Sevilla (fig. 1), se conoce arqueológicamente sólo por la documentación rescatada por D. Juan de Mata Carriazo, quien intervino tras la localización por unos obreros del famoso tesoro protohistórico que ha dado fama al yacimiento (Carriazo 1970, 1973 y 1978). El mismo excavador dedicó algunos capítulos de otras obras suyas al estudio e interpretación de este importante sitio (Carriazo 1974: 220-406); y no han sido pocos los investigadores que han retomado los testimonios exhumados en dicho cabezo para abordar muchos de los problemas que la arqueología tartésica tiene todavía planteados. Se ha ofrecido incluso una relectura de ciertos vasos prehistóricos infrapuestos a la estratigrafía del primer milenio a.C. (Ruiz Mata 1978-79: 45-46), que evidencian una ocupación durante el Calcolítico campaniforme no valorada adecuadamente por Carriazo, quien consideró en parte neolíticos dichos materiales (Carriazo 1973: fig. 418, izquierda).
Por lo que se refiere a la fase tartésica del asentamiento, son tantas las alusiones y estudios parciales de lo que en su día se extrajo del Carambolo, que sólo la enumeración de esas obras rebasaría los límites físicos de este trabajo y la intención con que ahora queremos entrar en el tema. De ahí que sólo traigamos aquí a colación -y exclusivamente en su justo momento - aquellas que de alguna forma inciden en los aspectos que ahora nos interesan, que son los que tienen que ver con la hipótesis, apuntada ya por Carriazo y luego recogida por otros autores según se verá, de que en este promontorio de la comarca sevillana del Aljarafe existió en su día un lugar de culto, y de que gran parte de la documentación arqueológica que se obtuvo, tanto de la parte
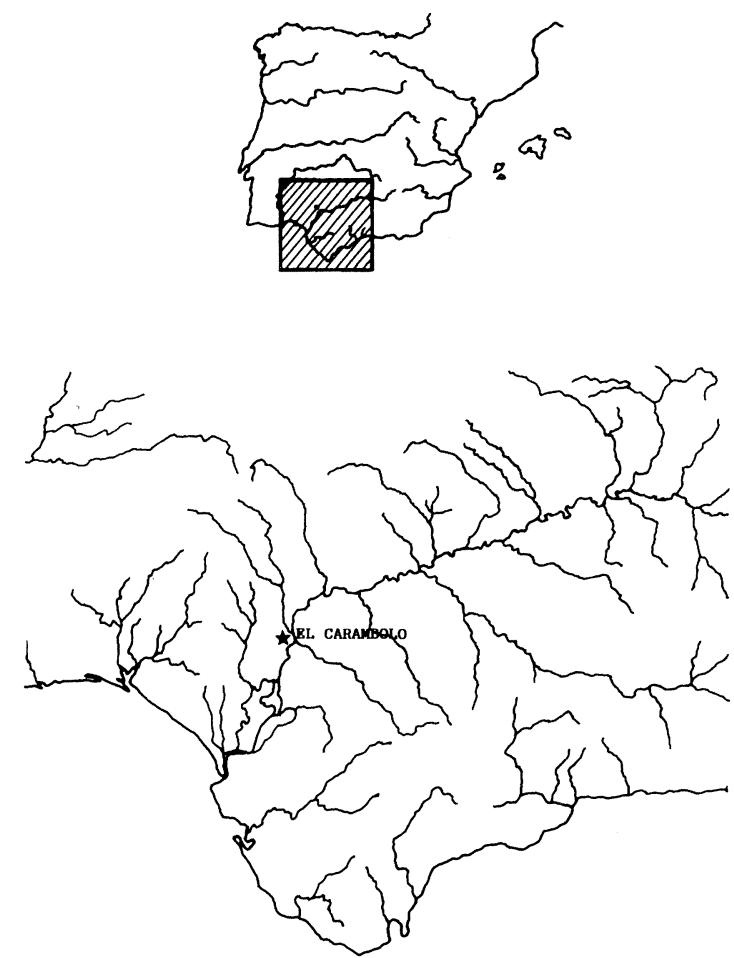

Fig. 1.-Lugar de emplazamiento del Carambolo. 
alta del cerro como de lo que se ha denominado «poblado bajo», puede ser interpretada desde este enfoque.

En las distintas obras en las que Carriazo abordó el estudio del Carambolo, él mismo apuntó esta hipótesis; sobre todo porque aludió al carácter ritual de algunos de los restos materiales descubiertos en su intervención o a la propia vinculación del tesoro con el mundo religioso de algunas culturas mediterráneas contemporáneas de la tartésica. Así, los paralelos tipológicos y funcionales de las distintas piezas del conjunto áureo fueron recopilados entre figurillas sagradas e imágenes de dioses (por ejemplo, Carriazo 1973: 162-175); y la alusión a objetos de culto se hace también cuando analiza las pilas monolíticas de piedra (Carriazo 1973: 294-295; 1974: fig. 42).

Más tarde, A. Blanco Freijeiro sostuvo explícitamente la existencia de un recinto sagrado en el cerro, que identificó en concreto con la estructura en la que apareció oculto el tesoro, y que la literatura arqueológica conoce desde la intervención de $\mathrm{Ca}$ rriazo indistintamente como «fondo de cabaña»y «Carambolo Alto». En este caso, Blanco enfatizó la importancia y riqueza de la cerámica pintada con geometrismos al estilo que desde su aparición allí se conoce como «tipo Carambolo», y recordó los paralelos egeos de ciertos templos de humilde y pobre consistencia arquitectónica pero de fecundos ajuares (Blanco 1979: 95-96). Igualmente, aclaró la procedencia de dicho cabezo de la figurilla en bronce que representa a la diosa fenicia Astarté y que se conserva en el Museo Arqueológico de Sevilla, imagen que habría aparecido en el propio «poblado alto» sólo unos días antes del hallazgo del tesoro (Amores 1995: 167).

Recientemente, se ha valorado la presencia de cáscaras de huevo de avestruz en el «fondo de cabaña» como un indicio más de que no estaríamos ante una común y simple vivienda de finales de la Edad del Bronce, sino ante un posible pozo de ofrendas relacionado de alguna manera con actos litúrgicos (Belén y Escacena e.p.a).

Desde estos planteamientos, el presente artículo pretende contribuir de alguna forma a la hipótesis que defiende el carácter sagrado del lugar. No se trataría tanto de sostener la existencia de un templo en un poblado - algo por lo demás que podría haber sido un hecho frecuente en todos los asentamientos de cierta importancia de la zona- como de explicar el sitio del Carambolo básicamente como un centro ceremonial con dependencias anexas, posiblemente en íntima relación desde sus inicios con la vecina Sevilla, fundada también por las mismas fechas. Con esta intención, abordamos el estudio funcional de una pieza de bronce que Carriazo dio a conocer bajo la denominación con que la bautizaron los propios obreros que intervinieron en los trabajos arqueológicos practicados en el lugar: «la trompeta de Argantonio». El excavador propuso tres hipótesis: pie de caldero, soporte de tipo carrete y base de candelero (Carriazo 1970: 100-102; 1973: 321-325). Las tres han permanecido hasta hoy sin trabajar en mayor profundidad que aquella con que la abordó Carriazo, de manera que los catálogos y estudios posteriores a su hallazgo referentes a tales objetos no han incluido casi nunca este ejemplar del Carambolo. De las tres funciones, intentaremos demostrar que se trata del pie abocinado de un quemaperfumes ritual o thymiaterion, cuya presencia en El Carambolo supondría un aporte documental más a la hipótesis que sostiene un papel religioso para este yacimiento.

\section{CONTEXTO ESTRATIGRÁFICO}

En octubre de 1958 se practicaron excavaciones arqueológicas en el lugar donde, de modo fortuito, habían aparecido las joyas que componen el tesoro del Carambolo. La superficie excavada fue pequeña, pero la riqueza de los materiales salidos del fondo de cabaña en el que se ocultó el tesoro tentó a su excavador a seguir trabajando en aquel lugar.

El convencimiento de que allí se escondía un núcleo de habitación estaba avalado por los fragmentos cerámicos repartidos por la superficie del cerro, por las fotografías aéreas del sitio, en las que se observaba en su parte septentrional un recinto circular aproximadamente dos metros más alto que el resto del terreno circundante, y por el propio valor geoestratégico del Carambolo como punto elevado que permite el dominio y control visual de la entrada al valle del Guadalquivir y de la vecina Sevilla.

Los trabajos arqueológicos en la vertiente septentrional del cabezo comenzaron a finales de mayo de 1960 con la apertura de pozos de sondeo para la detección de restos que determinasen la posible ocupación del lugar en tiempos protohistóricos. Si bien en un principio no se encontró otra cosa que algún que otro fragmento de cerámica, en el pozo $\mathrm{n}^{\circ}$ 16 , situado en el lado noreste del recinto circular que se veía en la fotografía aérea y casi al pie del talud del campo de tiro, se descubrió el primer muro del «poblado bajo» del Carambolo (Carriazo 1970: 72-73; 1973: 236-286).

En este sector del yacimiento se excavó una su- 
perficie de $375 \mathrm{~m}^{2}$ y se detectaron cuatro niveles arqueológicos que correspondían a cuatro fases de ocupación, no observándose hiato alguno ni cambios bruscos entre un estrato y otro, aunque la orientación de los muros y los ajuares variaban sensiblemente entre los estratos III y IV.

El asentamiento disponía de estructuras de habitación de planta rectangular con cimientos de piedra y muros de adobe. El interior de las estructuras estaba compartimentado en estancias dedicadas a diferentes usos y funciones.

La «Trompeta de Argantonio» procede del área que Carriazo denominó «Sector noreste». Apareció junto al borde oriental del muro detectado en el pozo de sondeo $\mathrm{n}^{\circ} 16$, a una profundidad de 1,15 metros. Dicho muro pudo ser el cimiento que sustentara una de las estructuras de habitación del estrato III. Por el material allí recuperado y por su distribución interna, dicho ámbito fue denominado «cocina». Su planta es rectangular, con unas dimensiones de 1,50 metros de largo por 1,25 metros de ancho. Junto a la entrada presentaba un banco o poyete empedrado, y al pie de éste, pegado al muro medianero con una estructura del estrato II, un segundo poyete de menor tamaño que aún conservaba sobre él la mitad inferior de un vaso cerámico de gran capacidad. Delante del muro divisorio aparecieron varios niveles de hogares y restos de vajilla. Un pavimento de fragmentos de cerámica cubría parcialmente la estancia (Carriazo 1970: 73; 1973: 270-272).

Se cribó toda la tierra procedente de la «cocina», pero no se encontraron más piezas que correspondieran al resto del objeto que estudiamos. Por lo demás, el ajuar de la habitación consistía en fragmentos cerámicos (algunos de grandes vasos contenedores) y molinos de mano, sin darnos su excavador más detalles que nos ayuden a interpretar el contexto de aparición de nuestro bronce.

\section{DESCRIPCIÓN DE LA PIEZA (figs. 2-5)}

El objeto que estudiamos está expuesto actualmente en la sala dedicada al Carambolo en el Museo Arqueológico Provincial de Sevilla (ref. 14.565). Lo forman dos partes distintas: una acampanada (pieza A -inferior-) y otra de tendencia ligeramente troncocónica (pieza B - superior-) ${ }^{1}$. Ambas se hicieron en bronce (Carriazo 1970: 100102; 1973: 321-325).

\footnotetext{
1 Carriazo describe esta parte como cilíndrica tubular.
}

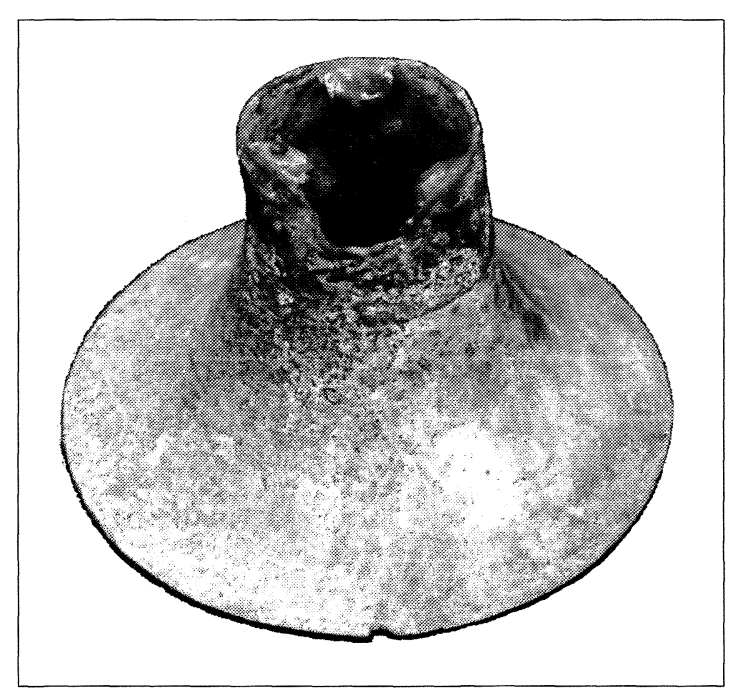

Fig. 2.-La «Trompeta de Argantonio».

En conjunto (fig. 3), sus dimensiones son las siguientes ${ }^{2}$ : Altura, $101,00 \mathrm{~mm}$. Diámetro mayor, $178,00 \mathrm{~mm}$. Diámetro menor, $64,50 \mathrm{~mm}$. Grosor paredes, $2,50 \mathrm{~mm}$.

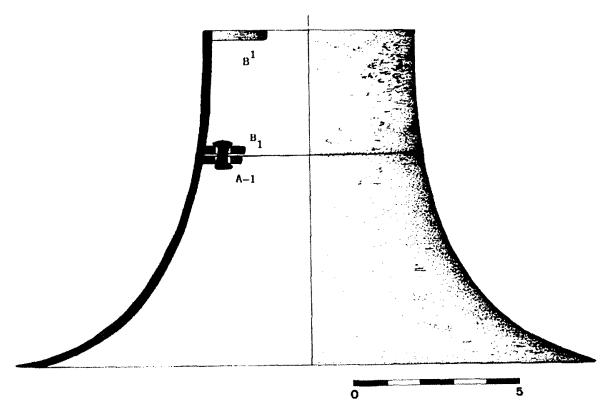

Fig. 3.-Perfil de la «Trompeta de Argantonio». Escala 1/3.

Descompuesta en sus distintas partes, estos dos elementos corresponden a:

Pieza A (fig. 4):

Pie abocinado con las siguientes medidas: Altura, 64,00 mm. Diámetro inferior, 178,00 mm. Diámetro superior, $69,00 \mathrm{~mm}$. Grosor paredes, 2,50 $\mathrm{mm}$.

Pieza $B$ (fig. 5):

Tronco de cono con las siguientes medidas: Altura, 37,00 mm. Diámetro inferior, 69,00 mm. Diámetro superior, $64,50 \mathrm{~mm}$. Grosor paredes, 2,50 $\mathrm{mm}$.

${ }^{2}$ EI hecho de que la pieza presente diversas abolladuras explica las ligeras diferencias entre las medidas ofrecidas por Carriazo y las nuestras. 


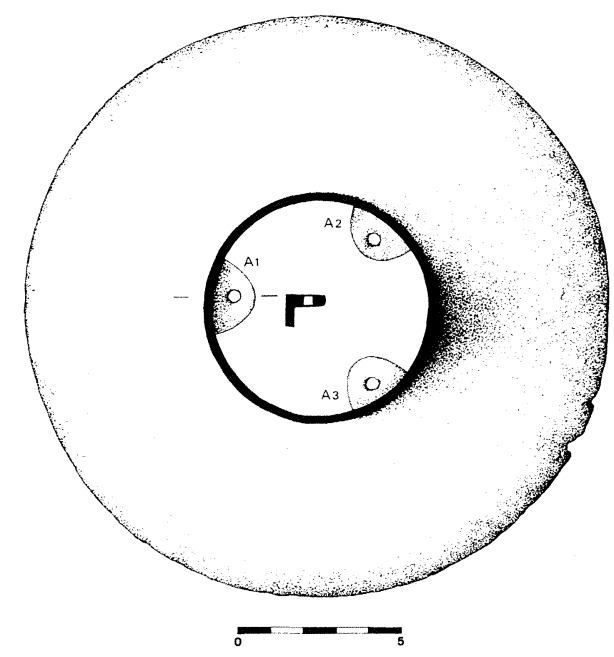

Fig. 4.-Pieza inferior (A). Escala 1/3.

La unión de las dos piezas que componen nuestro bronce se aseguró mediante tres pares de charnelas perforadas cruzadas por pasadores remachados. En la parte A, estas pletinas presentan planta semicircular. En la B son rectangulares en la parte inferior y algo más irregulares - a veces de tendencia semicircular (caso de las pestañas $\mathrm{B}^{1}$ y $\mathrm{B}^{2}$ ) - en la superior. Se unieron a las superficies internas de ambas piezas mediante soldadura.

Se conservan los tres pasadores que unen las piezas A y B. En cambio, de los remaches que trabarían este conjunto con el cuerpo superior (hoy perdido) sólo ha permanecido el de la charnela $\mathrm{B}^{3}$ (fig. $5)$. De este lote de pestañas, la $B^{2}$ presenta aún la perforación, mientras que la $\mathrm{B}^{1}$ la tiene obstruida por concreciones metálicas ${ }^{3}$.

Desde el punto de vista técnico, se observa un contraste entre el tratamiento de la lámina de bronce con que se elaboró la parte acampanada (pieza A) y el de la troncocónica (pieza B). En este segundo caso, la superficie es más irregular, el grosor menos uniforme, la pátina más rugosa y el color verde intenso, mientras que en la acampanada la superficie es más fina y regular. Carriazo (1970: 101; 1973: 322) apuntó que la calidad del bronce de una pieza y otra no era la misma y por ello se deformó y fracturó el borde alto de la superior, mientras que la otra no sufrió alteración alguna porque el metal sería de mejor calidad y por ende más resistente. En cualquier caso, parece que nuestro objeto se amortizó parcialmente como chatarra después de su primer uso como posible thymiaterion, pues la muesca y

${ }^{3}$ Carriazo creyó que esta pletina ni siquiera llegó a perforarse.
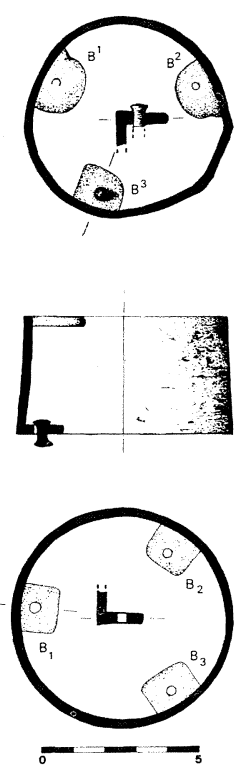

Fig. 5.-Pieza superior (B). Escala 1/3.

las torceduras que la pieza B presenta en su borde superior sugieren esta posibilidad. Tal propuesta ha sido barajada, de hecho, para otros tipos de incensarios de finales de la Edad del Bronce (Ruiz-Gálvez 1993: 52) ${ }^{4}$.

\section{ANÁLISIS FUNCIONAL}

Al presentar por vez primera esta pieza, Carriazo buscó paralelos tipológicos para la misma y ofreció tres posibles explicaciones funcionales (Carriazo 1970: 100-102; 1973: 323-325). La acumulación desde entonces de muchos más objetos de bronce del mundo tartésico y fenicio en el sur de la península ibérica, permite hoy contar con un repertorio de evidencias más precisas a la hora de proponer un papel específico para este pie.

Por su similitud en dimensiones y silueta, esta pieza de bronce fue asociada a los soportes de carrete de cerámica que también procedían del propio poblado bajo. Como paralelos se propusieron uno de cerámica marrón espatulada, otro del tipo gris «ampuritana»y un tercero de barniz rojo (Carriazo 1973: 323).

El autor también sugiere que puede tratarse del pie de un gran vaso de bronce o caldero, como los que en el mundo villanoviano y etrusco se usaron para urnas cinerarias, lo que vendría reforzado igualmente por su afinidad formal con el repertorio

${ }^{4}$ En contra de esta idea, Mederos y Harrison 1996: 250. 
cerámico del bucchero etrusco (Carriazo 1973: 323).

La tercera interpretación se refiere a un objeto ritual, de modo que Carriazo no cree del todo desacertado «... que nuestro bronce haya sostenido una pieza de adorno del tipo de los Candeleros de Lebrija» (Carriazo 1970: 100).

Un análisis detallado de estas tres propuestas presenta más argumentos a favor de la tercera, la que considera esta pieza el pie de un quemaperfumes.

Con respecto a que hubiera sido un soporte de carrete, se observa de hecho cierta similitud formal. Sin embargo, los soportes en bronce procedentes del mundo tartésico se fabricaron en una sola pieza. Esto se observa, por ejemplo, en los de la tumba 17 de la necrópolis de La Joya (Garrido y Orta 1978: 95 y 182, fig. 62), así como en el del túmulo $\mathrm{H}$ de Setefilla (Garrido y Orta 1978: 182) ${ }^{5}$. Por lo demás, por estar fabricados en una sola pieza, los carretes llevan baquetones en su parte central como refuerzo, característica ausente de la pieza del Carambolo.

A favor de una posible interpretación como base de caldero convendría recordar el viaje de Kolaios de Samos a Tartessos (Herodoto IV, 152), porque entre los presentes que llevó a su tierra figuraba precisamente un lebes de bronce. Pero el inconveniente principal reside en que estos recipientes, cuando llevan pie cónico, como ocurre en algunos ejemplares etruscos (Jacobsthal 1956: 48 y fig. 217; Pallottino 1965: lám. IV), éste se sujeta a la parte superior mediante otros mecanismos; por el contrario, a modo de pie se usaba generalmente un trípode o un soporte cónico como los que el propio Carriazo (1973: 323) recoge del mundo villanoviano. En este caso, la base no se soldaba o ensamblaba al caldero, sino que constituía una pieza independiente. De ahí que el sistema de engranaje superior de nuestro pie, destinado a unirlo con otras piezas superpuestas, impida darle esta función.

La tercera atribución sugerida por Carriazo (1970: 100) relaciona la pieza del Carambolo con un candelero como los ejemplares de oro aparecidos en Lebrija (Almagro 1964). En este caso hemos de tomar la hipótesis de Carriazo como una propuesta genérica que vincularía la pieza a las distintas modalidades de thymiateria orientalizantes conocidos en el Mediterráneo occidental. Y es en este terreno

${ }^{5}$ Esta pieza de Setefilla fue publicada por Bonsor y Thouvenot, quienes la dieron por boca de jarro (Bonsor y Thouvenot 1928: 24). Posteriormente, García y Bellido (1970: 35-37) sostuvo la misma interpretación. M.E. Aubet, por último, defendió también esta propuesta, si bien atribuyó el objeto a un subtipo distinto (Aubet 1973: 9-11, lám. Ib, fig. 2) donde el ejemplar del Carambolo encuentra, como veremos, sus paralelos más estrechos.

La forma acampanada del pie permite incluirlo de hecho en el tipo C de la sistematización de AlmagroGorbea (1974: 49), o en el grupo III de la clasificación propuesta por De la Bandera y Ferrer (1994a: 52-54), constituyendo la pieza del Carambolo en realidad sólo una pequeña variante del conjunto. Se trataría de thymiateria con pie o soporte de tendencia cónica y rematados en su parte superior por la típica cazoleta donde se quemaría el incienso. A este mismo lote pertenecerían ejemplares que recuerdan muy de cerca al del Carambolo (fig. 6): el del túmulo A de Los Higuerones de Cástulo (Blázquez 1975: 263-268, fig. 10, lám. 94A; Blázquez y Valiente 1982: 416-418, Abb. 11), el conservado en la Walters Art Gallery de Baltimore (Niemeyer 1970: 97-98), el de Villagarcía de la Torre, Badajoz (De la Bandera y Ferrer 1994b: 42-43, fig. 2), y el del Cerro del Peñón (Niemeyer y Schubart 1965: 76 y fig. 1). Todos ellos presentan en sus bases algún sistema de ensamblaje con las piezas superiores, como serían clavospasadores que atraviesan horizontalmente la parte superior del pie o elementos a rosca. El mecanismo de unión más parecido al de la pieza del Carambolo es el que fija en el ejemplar de Villagarcía de la Torre parte del cuerpo del quemaperfumes a las figurillas femeninas que, a modo de cariátides, sostienen el braserillo donde se quemaba el perfume ritual (De la Bandera y Ferrer 1994b: 44, figs. 2 y 8).

\section{AMBIENTE CULTURAL Y CRONOLÓGICO}

Los paralelos más evidentes de la pieza que hemos identificado como base de un thymiaterion llevan su cronología al siglo vir a.C. (Almagro-Gorbea 1974: 53), fecha de plenitud tanto de la colonización fenicia en Occidente como de la orientalización de Tartessos (Aubet 1987: 249). Parece que también durante este siglo El Carambolo conoció uno de sus momentos álgidos, pues a esos momentos corresponde la fecha más antigua de elaboración del tesoro (De la Bandera 1984: 400; y 1987: 468; Perea 1991: 211-212). Sin embargo, aún permanecen sin solución muchos de los problemas planteados a raíz de la excavación de este yacimiento. De hecho, en el contexto del Bajo Guadalquivir, El Carambolo ocupa un lugar destacado por la fecunda literatura a la que ha dado origen y por las muchas discusiones sobre temas arqueológicos que ha promovido. No insistiremos ahora en lo que se refiere a la función desempeñada por este yacimiento, porque dicho asunto es en realidad el tema de fondo de 
nuestro presente debate $\mathrm{y}$, por tanto, de nuestras conclusiones. En cambio, sí conviene hacer unas cuantas precisiones acerca de su cronología fundacional y de las razones y fecha de su muerte, porque también éstas pueden dar cuenta de la razón de ser del asentamiento.

Por lo que se refiere a su más antigua ocupación, ya hemos señalado antes la existencia de materiales campaniformes que ilustrarían una fase eneolítica reciente como primer hábitat. Pero este ensayo inicial no tuvo continuidad hasta época tartésica. De hecho, cada vez más yacimientos de Andalucía occidental vienen confirmandó la imposibilidad de sostener un periodo epicalcolítico durante la segunda mitad del segundo milenio a.C., al menos lo suficientemente largo como para enlazar directamente con el Bronce Final del Bajo Guadalquivir según se

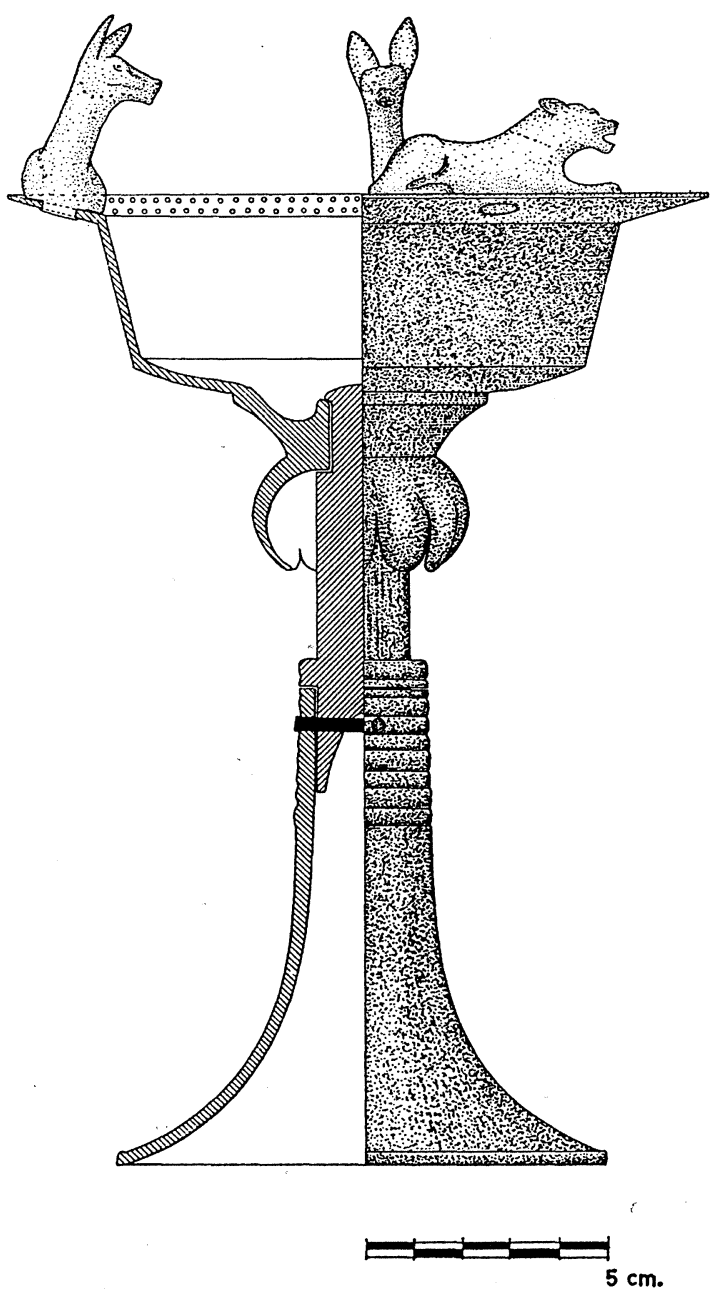

1
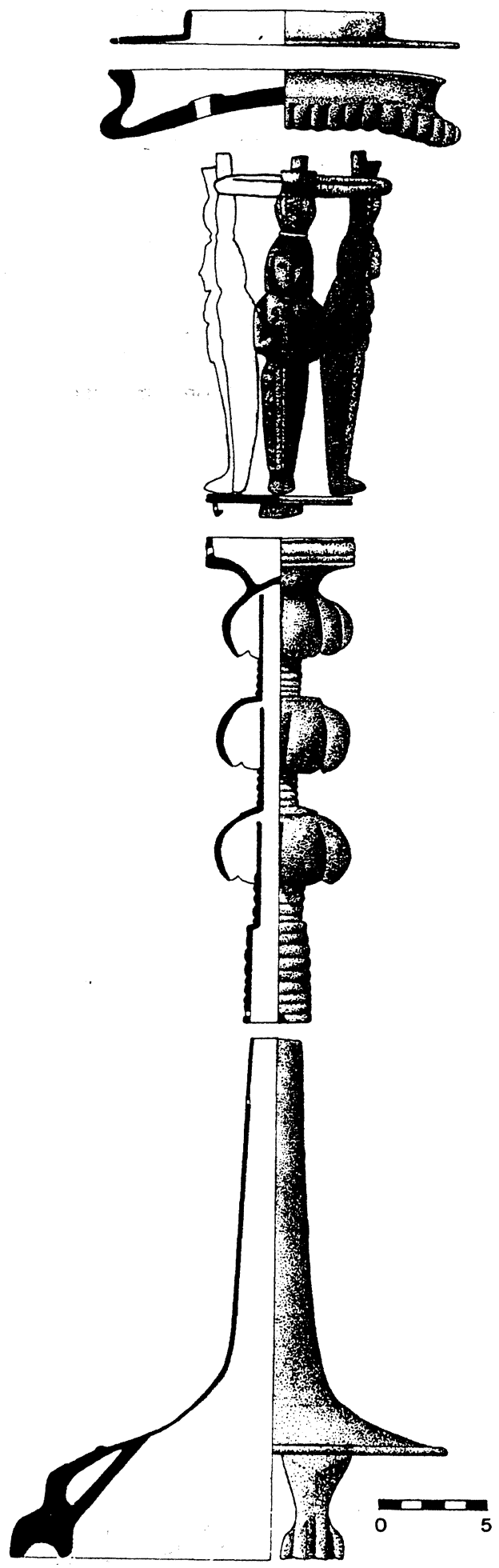

2

Fig. 6.-Algunos paralelos de la pieza del Carambolo: 1, Túmulo A de Los Higuerones de Cástulo (según Blázquez 1975); 2, Villagarcía de la Torre, Badajoz (según De la Bandera y Ferrer 1994b). 
ha propuesto en ocasiones (Harrison y otros 1976: 86; Fernández Gómez y Alonso 1985: 19-21). Así, Setefilla (Aubet y otros 1983) o El Berrueco de Medina Sidonia (Escacena y De Frutos 1985) habrían demostrado que entre la Edad del Cobre y la fase tartésica se desarrollaron grupos culturales del Bronce Pleno emparentados con el mundo argárico y con el horizonte de las Cistas del Suroeste. Estos contextos, que poco a poco empezamos a conocer en el mismo Aljarafe (Buero y otros 1978; Escacena y otros 1996: 20), no aparecen sin embargo en El Carambolo. En consecuencia, la ocupación de época tartésica hay que verla como una fundación nueva, que debe de obedecer a razones distintas a las del primer poblado del Cobre o, en cualquier caso, estar inserta en los patrones de asentamiento de los grupos humanos protohistóricos que a partir de finales de la Edad del Bronce tomaron el control de la zona.

La cronología de esta reocupación se mueve todavía entre dos posiciones irreconciliables. De un lado se ha defendido la existencia de unos niveles anteriores a la colonización fenicia de las costas andaluzas. Esta perspectiva cuenta con bastantes partidarios y ha recibido un nuevo impulso a raíz de dos publicaciones recientes de la profesora Aubet donde se precisan determinadas cuestiones estratigráficas del yacimiento (Aubet 1992; 1992-93). Por otra parte, con base en las propias observaciones de Carriazo y en la revisión de algunas cerámicas procedentes del Carambolo Alto, otros autores han propuesto que los estratos tartésicos más antiguos no serían en ningún caso precoloniales, sino básicamente contemporáneos a la llegada de los fenicios al Bajo Guadalquivir (Amores 1995: 167; Escacena y Belén 1991: 18-19). Esta segunda posición cuenta con menos defensores y sostiene además que la fundación del Carambolo pudo estar directamente relacionada con la de la propia Sevilla (Belén y Escacena e.p.a), que está documentada arqueológicamente en esa fecha (Collantes de Terán 1977: 37-54; Campos y otros 1988: 21), y cuyo primer nombre (Spal) podría ser de origen fenicio (Díaz Tejera 1982: 20; Lipinski 1984: 100). El problema de la cronología inicial del asentamiento no está, pues, resuelto, y ha tenido como caballo de batalla la presencia o no de cerámica a torno en el estrato más profundo del Carambolo Alto.

Más clara parece estar la fecha de abandono del sitio, si bien también aquí han surgido leves discrepancias. Sabemos al menos que el cabezo no conoció una ocupación durante la fase plena y tardía del mundo turdetano de la segunda Edad del Hierro. El mismo hecho de que el nombre antiguo del asentamiento no se conservara en las fuentes escritas de época clásica certificaría una muerte muy anterior a la conquista del territorio por Roma; sobre todo porque conocemos a través de estas referencias literarias otros topónimos de sitios muy cercanos al Carambolo: Ilipa (Alcalá del Río), Hispalis (Sevilla), Osset (San Juan de Aznalfarache), Caura (Coria del Río), Orippo (Torre de los Herberos, en Dos Hermanas), etc. La propia ocultación del tesoro a fines del siglo VI a.C. parece coincidir con la etapa última del asentamiento (Escacena 1993: 195), en circunstancias que hablan de una clara situación de peligro en la zona. Pero otros investigadores quieren ver en El Carambolo materiales anfóricos que llegarían tal vez al siglo iv a.C. (Rodero 1995: 67 y 221). En consecuencia, tampoco la cronología final está libre de dudas, con lo que urge un análisis más profundo del problema.

Con relación a estos dos asuntos, principio y final del Carambolo, poco se ha propuesto para indagar en las razones por las que dicho enclave surgió y luego llegó a desaparecer sin cuajar en una verdadera ciudad prerromana. $Y$ desde luego nunca se han puesto en relación ambos fenómenos, de forma que una misma causa pueda argüirse como la razón de ser de su nacimiento y de su muerte: el papel desempeñado en su día por el asentamiento. Si éste fue el de cobijar un importante santuario, según la hipótesis con que aquí trabajamos, los límites iniciales y finales de la ocupación pudieron tener que ver muy directamente con los fenómenos de implantación poblacional de las grupos humanos que habitaron la zona y con los intereses que les involucraron en la explotación de la comarca.

\section{RECAPITULACIÓN Y CONCLUSIONES}

Hemos abordado en este estudio el análisis del objeto de bronce procedente del Carambolo que los mismos obreros que intervinieron en las excavaciones de Carriazo denominaron «La Trompeta de $\mathrm{Ar}$ gantonio» (Carriazo 1973: 272). Ha sido nuestra intención aclarar la función de esta pieza, en la idea de que con ello contribuíamos a conocer más en profundidad el carácter que el sitio tuvo en su día, para lo cual hemos trabajado en la hipótesis que sostiene la existencia en dicho promontorio de un lugar de culto, una opinión no sólo propuesta por los investigadores especialidados en arqueología sino recogida también a partir de estos estudios por obras de tipo más general y divulgativo (Morales Padrón 1988: 48).

De las tres hipótesis barajadas por Carriazo a la hora de buscarle paralelos formales y funcionales, la 
que le atribuye el papel de un pie de quemaperfumes ritual resulta la más verosímil. Así, la presencia de un thymiaterion en El Carambolo contribuiría positivamente a sostener la existencia en el lugar de un recinto sagrado como Blanco imaginó, porque estas piezas de culto, asociadas a ritos de origen oriental e introducidas en la península ibérica a raíz de la expansión fenicia por el Mediterráneo oeste, se han localizado casi siempre - por lo menos cuando conocemos bien las circunstancias en que se hallaronen ambientes cultuales, fuesen o no funerarios.

Estas circunstancias se observan por ejemplo en el ejemplar de Alhonoz. Este asentamiento sevillano proporcionó en la misma zona de procedencia del thymiaterion de bronce una serie de objetos de culto a lo largo de una secuencia estratigráfica que cubre casi todos los tiempos protohistóricos. De allí procede, en efecto, un exvoto de plata con la representación de dos ojos (López Palomo 1981a: lám. III; 1981b: 251-253), así como una figura de Minerva en bronce (López Palomo 1981a: lám. II; 1981b: 249-251). En esa misma área el excavador localizó una enorme concentración de recipientes cerámicos que creyó en principio el lugar de fabricación y/o venta de un taller de alfarero (López Palomo 1981a: 55-81), que diversos autores han reinterpretado como un posible lote de ofrendas (Almagro-Gorbea y Domínguez de la Concha 1988-89: 365; Belén y Escacena e.p.b; De la Bandera 1994a: 57), sobre todo por las semejanzas que pueden establecerse entre dicho conjunto y otras concentraciones vasculares procedentes de sitios de clara función religiosa (cf. Beirâo y otros 1985: 56-61). La pequeñez de estos recipientes de Alhonoz y las decoraciones simbólicas que ostentan apuntan igualmente a esta función ritual (Escacena 1992).

El ejemplar de Huelva procede de la tumba 17 de la necrópolis de La Joya, donde acompañaba, entre otros objetos, a un jarro y a un brasero, conformando las tres piezas - todas ellas en bronceel ajuar típico de los ritos funerarios de las sepulturas fenicias hispanas (Garrido y Orta 1978: 64, 91 y 177-178).

Las piezas de Cástulo, por último, se localizaron igualmente en un ambiente funerario. Una procede del túmulo A de Los Higuerones (Blázquez 1975: 263-271; Blázquez y Valiente 1982: 416-418). La otra del Estacar de Robarinas (De la Bandera y Ferrer e.p. ${ }^{6}$.

En síntesis, los cuatro paralelos andaluces citados certifican, de alguna manera, que los lugares de

${ }^{6}$ Este pebetero fue interpretado primeramente por Blanco como parte de un caldero (Blanco 1963: 60). procedencia forman parte de ambientes sagrados, unas veces como santuarios y otras como cementerios. Si esta condición puede ser aplicada al Carambolo, estaríamos en consecuencia ante un dato más que apoyaría la hipótesis propuesta en su día por Blanco de interpretar el "poblado alto» como un lugar de culto. Este hipotético centro ceremonial, situado a occidente de la Sevilla protohistórica, pudo estar en consecuencia directamente vinculado a esta ciudad y a sus necesidades cultuales, la de la comunidad fenicia que la fundó según sugiere el topónimo Spal y sostiene la tradición al menos desde Rodrigo Caro (1634: 3-4). En conjunto, la ciudad, situada al fondo del antiguo estuario del Guadalquivir, y - de ser así- su cercano santuario, ubicado frente a ella sobre una de las colinas más altas de la cornisa oriental del Aljarafe, al otro lado del río (fig. 7), responderían a las características básicas de localización de las colonias fenicias hispanas (Pellicer y otros 1977: 220-222).

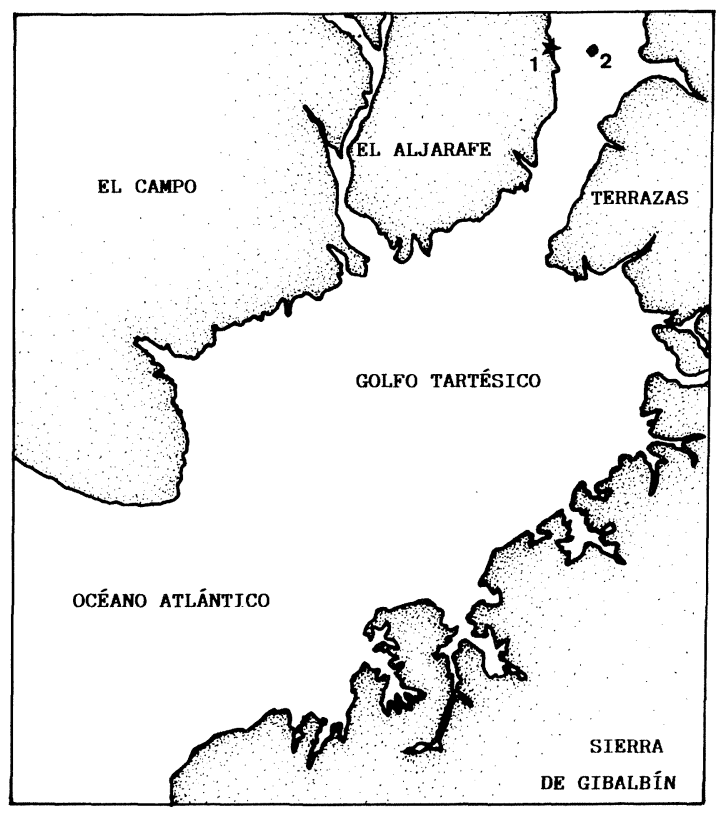

Fig. 7.-Reconstrucción de la paleodesembocadura del Guadalquivir en época tartésica (a partir de Ménanteau 1982), con la situación del yacimiento del que procede la pieza estudiada (1: El Carambolo) y de Sevilla, sobre una peque-

ña isla al fondo del antiguo estuario del río (2: Spal).

Ambos enclaves deberían por tanto ser estudiados y comprendidos como un todo, si bien, rebasada la fecha de apogeo de la presencia oriental en las tierras del Bajo Guadalquivir a partir de mediados del siglo VI a.C., la antigua colonia comercial pudo seguir con vida a la vez que moría el santuario bajo 
el nuevo predominio de Gadir. De manera que la inauguración y el abandono del Carambolo pueden ser el reflejo directo de los acontecimientos históricos que limitaron el orto y el ocaso de la etapa más floreciente de la colonización fenicia en Tartessos.

\section{BIBLIOGRAFÍA}

Almagro, M. (1964): «Los thymateria llamados candelabros de Lebrija», Trabajos de Prehistoria XIII.

Almagro-Gorbea, M. (1974): «Dos thymiateria chipriotas procedentes de la Península Ibérica», Miscelánea. XXV Aniversario de Cursos de Ampurias, 41-55. Barcelona.

Almagro-Gorbea, M. y Domínguez de la Concha, A. (1988-89): «El palacio de Cancho Roano y sus paralelos arquitectónicos y funcionales», $\mathrm{Ze}$ phyrvs XLI-XLII, 339-382.

Amores, F. (1995): «La cerámica pintada estilo Carambolo: una revisión necesaria de su cronología», Tartessos 25 años después 1968-1993 (Jerez de la Frontera), 159-178. Ayuntamiento de Jerez.

Aubet, M.E. (1973): «Materiales púnico-tartesios de la necrópolis de Setefilla en la Colección Bonsor», Boletín del Seminario de Estudios de Arte y Arqueología XXXIX, 5-30.

- (1987): Tiro y las colonias fenicias de occidente. Barcelona, Bellaterra.

- (1992): «Maluquer y la renovación de la arqueología tartésica», en Excavaciones en «El Carambolo» (Sevilla) (Clásicos de la Arqueología de Huelva 5). Excma. Diputación Provincial de Huelva.

- (1992-93): «Maluquer y El Carambolo», Tabona VIII, vol. II, 329-350.

Aubet, M.E. y otros (1983): La Mesa de Setefilla. Lora del Río (Sevilla). Campaña de 1979 (Excavaciones Arqueológicas en España 122). Madrid, Ministerio de Cultura.

BeIrÃo, C. de M. y otros (1985): «Depósito votivo da II Idade do Ferro de Garvão. Notícia da primeira campanha de escavações», O Arqueólogo Português, série IV, 3, 45-136.

BELÉN, M. y EsCACENA, J.L. (e.p.a): «Interacción cultural fenicios-indígenas en el Bajo Guadalquivir», Homenaje al Prof. Fernando Gascó, en Kolaios 4.

- (e.p.b): «Economía y sociedad en la Turdetania de los siglos V-IV a.C.», en La Andalucía IberoTurdetana. Huelva.

Blanco, A. (1963): «El ajuar de una tumba de Cástulo», Archivo Español de Arqueología XXVI, 4069.
- (1979): Historia de Sevilla. I (1) La Ciudad Antigua (Desde la prehistoria a los visigodos). Sevilla, Universidad de Sevilla.

BLÁZQUEZ, J.M. (1975): Tartessos y los orígenes de la colonización fenicia en Occidente. Salamanca, Universidad de Salamanca.

Blázquez, J.M. y VAliente, J. (1982): «El poblado de La Muela y la fase orientalizante en Cástulo (Jaén)», en Niemeyer, H.G. (ed.), Phönizier im Westen (Madrider Beiträge 8), 407-428. Mainz.

Bonsor, G. y Thouvenot, R. (1928): Nécropole Ibérique de Setefilla (Lora del Río, Sevilla), Fouilles de 1926-1927, Paris.

BuEro, M.S. y otros (1978): «Yacimiento del Bronce en Santa Eufemia», Archivo Hispalense, $2^{\mathrm{a}}$ época, LXI, n 186, 59-64.

Campos, J. M. y otros (1988): Protohistoria de la Ciudad de Sevilla. El corte estratigráfico San Isidoro 85-6 (Monografías de Arqueología Andaluza / 1). Sevilla, Consejería de Cultura de la Junta de Andalucía.

CAro, R. (1634): Antigvedades, y Principado de la Ilvstrissima Civdad de Sevilla. Y Chorographia de sv Convento Ivridico, o Antigva Chancilleria. Sevilla, Andres Grande, Impressor de Libros.

Carriazo, J. de M. (1970): El tesoro y las primeras excavaciones en «El Carambolo» (Camas, Sevilla) (Excavaciones Arqueológicas en España 68). Madrid, Ministerio de Cultura.

- (1973): Tartesos y El Carambolo. Madrid, Ministerio de Educación y Ciencia.

- (1974): Protohistoria de Sevilla. Sevilla, Ayuntamiento de Sevilla.

- (1978): El Carambolo. Sevilla, Universidad de Sevilla.

Collantes de Terán, F. (1977): Contribución al estudio de la topografía sevillana en la Antigüedad y en la Edad Media. Sevilla, CSIC-Monte de Piedad y Caja de Ahorros de Sevilla.

De la Bandera, M.L. (1984): «Brazaletes peninsulares orientalizantes e ibéricos en metales nobles», Habis 15, 365-418.

- (1987): La joyería orientalizante e ibérica del s. VII al I a.C. (mitad sur peninsular). Sevilla, ed. en microfichas.

- y FERRER, E. (1994a): «Thymiateria orientalizantes en bronce. Nuevas aportaciones y consideraciones», en Sáez, P. y Ordóñez, S. (eds.), Homenaje al Profesor Presedo, 43-60. Sevilla, Universidad de Sevilla.

- (1994b): «El timiaterio orientalizante de Villagarcía de la Torre (Badajoz)», Archivo Español de Arqueología 67, 41-61.

- (e.p.): «Reconstrucción del ajuar de una tumba 
de Cástulo: ¿indicios de mestizaje?», Homenaje al Prof. Fernando Gascó, en Kolaios 4.

Díaz Tejera, A. (1982): Sevilla en los textos clásicos greco-latinos. Sevilla, Ayuntamiento de Sevilla.

EsCACENA, J.L. (1992): «Cerámicas votivas de Alhonoz», en Andalucía y el Mediterráneo, 118-119. Cádiz, Consejería de Cultura de la Junta de Andalucía.

- (1993): «De la muerte de Tartesos. Evidencias en el registro poblacional», Spal 2, 183-218.

- y Belén, M. (1991): «Sobre la cronología del horizonte fundacional de los asentamientos tartésicos», Cuadernos del Suroeste 2, 9-42.

Escacena, J.L. y De Frutos, G. (1985): «Estratigrafía de la Edad del Bronce en el Monte Berrueco (Medina Sidonia, Cádiz)», Noticiario Arqueológico Hispánico 24, 7-90. Madrid, Ministerio de Cultura.

EsCACENA, J.L. y otros (1996): «Caura protohistórica», Revista de Arqueología 184, 16-25.

FERNÁNDEZ Gómez, F. y Alonso, J. (1985): «Un fondo de cabaña campaniforme en la Universidad Laboral de Sevilla», Noticiario Arqueológico Hispánico 22, 7-26.

GARCíA y Bellido, A. (1970): «Algunas novedades sobre la arqueología púnico-tartessia», Archivo Español de Arqueología XLIII, 3-49.

GARRIDO, J.P. y ORTA, E.M. (1978): Excavaciones en la Necrópolis de «La Joya», Huelva. II $\left(3^{a}, 4^{a} y\right.$ $5^{a}$ campañas) (Excavaciones Arqueológicas en España 96). Madrid, Ministerio de Educación y Ciencia.

HARRISON, R.J. y otros (1976): «The Beaker Pottery from El Acebuchal, Carmona (Prov. Sevilla)», $M a-$ drider Mitteilungen 17, 79-141.

JACOBSTHAL, P. (1956): Greek pins and their connexions with Europe and Asia. Oxford, Clarendon Press.

LIPINSKI, E. (1984): «Vestiges phéniciens d'Andalousie», Orientalia Lovaniensia Periodica 15, 81-137.

LóPez PALOMo, L.A. (1981a): «Alhonoz (Excavacio- nes de 1973 a 1978)», Noticiario Arqueológico Hispánico 11, 33-188.

- (1981b): «Bronces y plata tartéssicos de Alhonoz y su hinterland», Zephyrvs XXXII-XXXIII, 245261.

Mederos, A. y Harrison, R.J. (1996): «'Placer de Dioses'». Incensarios en soportes con ruedas del Bronce Final de la Península Ibérica», en M.A. Querol y T. Chapa (eds.), Homenaje al Profesor Manuel Fernández-Miranda, en Complutum, Extra 6 (I), 237-253.

MÉnanteau, L. (1982): Les Marismas du Guadalquivir. Exemple de Transformation d'un Paysage Alluvial au Cours du Quaternaire Récent. Université de Paris-Sorbonne.

Morales Padrón, F. (1988): Guía Sentimental de Sevilla. Sevilla, Universidad de Sevilla.

Niemeyer, H.G. (1970): «Zum Thymiaterion vom Cerro del Peñón», Madrider Mitteilungen 11, 96-101.

- y Schubart, H. (1965): «Ein ostphönikisches Thymiaterion vom Cerro del Peñón (Almayate Bajo, Prov. Málaga)», Madrider Mitteilungen 6, 74-83.

Pallottino, M. (1965): Etruscología. Buenos Aires, Universidad de Buenos Aires.

Pellicer, M. y otros (1977): «Para una metodología de localización de colonias fenicias en las costas ibéricas: el Cerro del Prado», Habis 8, 217-251.

Perea, A. (1991): Orfebrería Prerromana. Arqueología del Oro. Madrid, Caja de Madrid-Comunidad de Madrid.

Rodero, A. (1995): Las Ánforas Prerromanas en Andalucía (Epigrafia e Antichità 13). Faenza, Fratelli Lega.

Ruiz-Gálvez, M. (1993): «El Occidente de la Península Ibérica, punto de encuentro entre el Mediterráneo y el Atlántico a fines de la Edad del Bronce», Complutum 4, 41-68.

RuIz MAtA, D. (1978-79): «Nuevos yacimientos campaniformes en la provincia de Sevilla», Cuadernos de Prehistoria y Arqueología de la Universidad Autónoma de Madrid 5-6, 41-57. 